\title{
The Effects of Automated Prompting and Self-Monitoring on Homework Completion for a Student with Attention Deficit Hyperactivity Disorder
}

\author{
Amy Blicha ${ }^{1} \&$ Phillip J. Belfiore ${ }^{1}$ \\ ${ }^{1}$ Department of Special Education, Mercyhurst University, Erie, Pennsylvania, USA \\ Correspondence: Phillip J. Belfiore, Department of Special Education, Mercyhurst University, 501 East $38^{\text {th }}$ \\ Street, Erie, PA, 16546, USA. Tel: 1-814-824-2267. E-mail: pbelfiore@mercyhurst.edu
}

Received: April 18, 2013

Accepted: May 22, $2013 \quad$ Online Published: July 12, 2013

doi:10.5539/jel.v2n3p51

URL: http://dx.doi.org/10.5539/jel.v2n3p51

\begin{abstract}
This study examined the effects of an intervention consisting of automated prompting and self-monitoring on the level of independent homework task completion for an elementary-age student with attention deficit hyperactivity disorder (ADHD). Instituting a single subject, within series ABAB design, the results showed a consistent increase and stability in homework task completion following the introduction of a vibrating alarm wristwatch and a self-monitoring homework routine checklist. Stable homework performance continued through the 5-month follow-up, as well as following a termination and change in medications which occurred during month two and three of the follow-up phase. Additionally, academic performance as measured by mathematics and language arts school term grades showed improvement. Results are discussed in light of parents as active co-problem-solvers, the role of applied behavioral action research, and the efficacy of self-management with students with ADHD.
\end{abstract}

Keywords: attention deficit hyperactivity disorder, self-monitoring, single subject research, homework, prompting

\section{Introduction}

\subsection{Introduction of the Problem}

Many studies have described, not surprisingly, students with attention and behavior challenges as at-risk for academic failure, including failures of homework completion and homework accuracy (e.g., Bryan \& Burstein, 2004; Currie, Lee, \& Scheeler, 2005; Merriman \& Codding, 2008; Olympia, Sheridan, Jenson, \& Andrews, 1994; Sheridan, 2009). Axelrod, Zhe, Haugen, \& Klein (2009) suggested these students often struggle with such homework behaviors as persisting in specific academic or organizational tasks requiring sustained attention, organizing homework materials and assignments, self-managing instructional time efficiently, completing homework independent of teacher prompting, and transferring homework from home to school or school to home.

At its' best, homework is an academically useful, proactive, and appropriate educational strategy intended to enhance study skills, time management, and self-discipline in students (Axelrod et al., 2009; Merriman \& Codding, 2008; Sheridan, 2009), while building an ongoing, interactive connection between school and home. More importantly, Axelrod et al., (2009) suggested improving homework accuracy, through the repetitive opportunities for academic responding that were learned during the school day, serves as a strategy to enhance academic performance by building fluency. In addition, once students master skills necessary for proficient homework completion in one academic area (e.g., mathematics), that homework skill set can readily generalize across other academic areas (e.g., language arts, science, social studies) (Belfiore \& Hutchinson, 1998; Currie et al., 2005).

Sheridan (2009) suggested that at its' worst, homework can act as a disruptive environmental event for families and school-age children who have not mastered what Belfiore \& Hutchinson (1998) described as academic routines. Academic routines may be defined as a task analysis, or chain of skills, necessary for academic success across a range of academic curriculum areas (e.g., homework completion, note taking, study strategies, test preparation), but skills not directly related to teaching strategies within a single academic curriculum area 
(Belfiore \& Hutchinson, 1998). Without the skill set to master academic routines such as homework completion, student with academic and behavioral challenges will be less well equipped to (a) effectively manage instructional time, (b) improve their academic performance, and/or (c) maintain academic gains long term.

\subsection{Importance of the Problem and Relevant Scholarship}

The result of inadequacies in homework completion is compounded when the home-school communication continuum is weak or not in place. Families that do not establish such communications as part of homework at home time exacerbate the academic concerns raised in the school setting. Although numerous researchers have argued that a home-school connection is needed to maximize student academic success (Bryan \& Burstein, 2004; Cancio, West, \& Young, 2004; Kim, Sheridan, Kwon, Koziol, 2013; Masten \& Coatsworth, 1998; Power, Werba, Watkins, Angelucci, \& Eiraldi, 2006), the effects of parent involvement in homework on student achievement are mixed (Patall, Cooper, \& Robinson, 2008). Possible reasons for these mix results may be (a) availability of resources in the home, (b) home scheduling, (c) home mentoring skills (Bryan \& Burstein, 2004; Patall et al., 2008), and (d) the need for buy-in by the home for interventions and assignments handed-down by the school. The home will be a much more willing partner with the school if the homework interventions are less time intensive and less complex (Axelrod et al., 2009). The partnership may be enhanced if the home is asked for feedback in the school-based intervention, or if the home shares in the homework intervention design. Strategies to improve homework completion are unlikely to be fruitful until all stakeholders are motivated to invest time and energy in building shared values regarding school success (Bryan \& Burstein, 2004).

Although homework has been described as the most common point of intersect among home, school, and student as it relates to formal academic learning (Hoover-Dempsey, Bassler, \& Burow, 1995), research on homework for students with disabilities, especially students with attention and learning challenges, has been limited (Cancio et al., 2004; Merriman \& Codding, 2008; Power et al., 2006). That said, home-school-based interventions targeting homework accuracy and completion must meet the needs of student, teacher, and family if they are to be effective long term.

Mathes and Bender (1997) brought attention to the benefits of self-regulation strategies, documenting the on-task behavior of all three students with Attention Deficit Hyperactivity Disorder (ADHD) improved significantly once a self-monitoring intervention was applied. Amato-Zech, Hoff, \& Doepke (2006) investigated the effects of an intervention package consisting of self-monitoring and an automated, antecedent prompt on on-task behavior of three fifth-grade students classified with multiple diagnoses including, speech and language impairment, learning disabilities, and/or social-emotional disturbance. The MotivAider ${ }^{\circledR}$, an electronic vibrating beeper, prompted students to self-record using a paper and pen their on-task or off-task behavior. During intervention, the students' on-task behavior increased from a baseline mean of $55 \%$ on-task to more than $90 \%$ on-task (Amato-Zech et al., 2006). The results of this study showed that students with learning and behavioral challenges can effectively self-monitor, resulting in positive behavior change. Additionally, the teachers in the study indicated the intervention was easy to implement within the context of the school day, and the intervention was accepted by students in the classroom (Amato-Zech et al., 2006).

In a similar study, Legge, DeBar, and Alber-Morgan (2010) evaluated the effects of the MotivAider ${ }^{\circledR}$ and self-monitoring on on-task behaviors and mathematics assignment completion for three elementary grade students with autism and other disabilities. All three students who participated had significant increases in on-task behavior once the Motivator and self-monitoring were in place (Legge et al., 2010).

Other researchers have also suggested that some aspect of self-regulation is a beneficial component to any homework intervention (e.g., Axelrod et al., 2009; Olympia et al., 1994). For example, Axelrod, et al., (2009) showed the effectiveness of a home-based self-management intervention for five students with attention and behavior deficits as improvement of on-task behavior during the self-monitoring intervention and fewer incomplete homework assignments during intervention. Additionally, in a review of research on self-regulation skills and homework, Ramdass \& Zimmerman (2011) concluded by suggesting the addition of a homework checklist, or routine, would assist student in developing time-management skills.

When mastered, self-management strategies have been shown to be effective for students with behavioral and attention deficits (e.g., Axelrod, et al., 2009; Mathes \& Bender, 1997). Adding a non-intrusive antecedent prompt should enhance the intervention by (a) informing students to initiate self-monitoring (e.g., Amato-Zech et al., 2006; Legge et al. 2010), as well as (b) requiring less reliance on teacher-directed instruction to initiate the academic task at hand. Cooperating with parents as equal partners allows for both a seamless/consistent intervention between home and school, and the assessment of long term maintenance of homework performance (e.g., Cancio et al., 2004). 


\subsection{Purpose of Research}

The purpose of this study was to examine the effects of an automated prompt and self-monitoring on the level of independent homework completion for an elementary age student with ADHD. As such, the purpose of this study extended the research on homework completion in three key areas, (a) SM as a strategy, reducing the teacher-directed role in classroom management while increasing student academic homework completion, (b) parents as active members of a school-home-based intervention, and (c) applied behavioral action research as a link between applied behavioral research and evidenced-based practices.

\section{Method}

\subsection{Participant and Setting}

Mark was a 10.6 year old boy, enrolled in a $5^{\text {th }}$ grade suburban elementary school, with a diagnosis of Attention Deficit Hyperactivity Disorder (ADHD). At the onset of this study he received one daily dose of pharmaceutical medication, Concerta $27 \mathrm{mg}$. at 8:00am before school. The medicine was time released and remained in one's system for approximately eight hours (Ortho-McNeil-Janssen Pharmaceutical, Inc., 2009). Mark was removed from Concerta at the end of month one of the follow-up phase. During month three of the follow-up phase Mark changed medication, to Focalin XR.

The National Institute of Mental Health described Attention Deficit Hyperactivity Disorder (ADHD) as a disorder that (a) impedes an individual's ability to hold focus, attention, and controlling behavior, and (b) includes hyperactivity (NIMH, 2008). The symptoms are thought to affect $3-7 \%$ of school-age children (Merriman \& Codding, 2008), and are categorized into predominantly hyperactive-impulsive, inattentive, and combined hyperactive-impulsive and inattentive (NIMH, 2008). Characteristics of children diagnosed with ADHD function at varying degrees of severity and include (a) inattention (e.g., easily distracted, loss of details, forgetful, frequently switch from one activity to another, and having difficulty focusing attention on organizing and completing a task), (b) hyperactivity (e.g., fidgeting, non-stop talking, and having difficulty doing a quiet task or activity, and/or (c) impulsivity (e.g., impatient and interrupting conversations or other activities) (NIMH, 2008).

Mark attended a neighborhood school, was on grade level for all academic subjects, and participated fully in the general educational classroom. Mark was referred for participation in this study by his parent (the first author) and the previous year's classroom teacher based on observations that Mark was not completing the homework from the previous day's assignment. Mark had the academic ability to complete the level of homework assigned in each academic subject area. Whatever homework Mark brought home in the evening, was always completed accurately and returned to school the following day. The classroom teacher and the first author indicated that the problem was that Mark did not bring home all the assignments requested by the teacher at the end of the day. Mark did not complete homework as a result of not collecting all homework assignments prior to leaving school, resulting in incomplete homework arriving at home in the evening, and further resulting in incomplete homework arriving at school the following morning. The academic issue was organizing homework assignments and materials to be brought home when school ended, and not completing homework accurately or returning homework to the school the following morning. Regardless, the general outcomes of not returning homework resulted in (a) lower grades as a result of missed academic points, (b) loss of study materials impacting future tests and exams, and /or (c) loss of recess or free time.

The $5^{\text {th }}$ grade classroom enrolled 23 students with one general education teacher who taught language arts (reading, writing, vocabulary, spelling, and grammar), and mathematics. Students moved to a different general education teacher and classroom for science and social studies. Language arts and mathematics were taught each day. Prior to, and continuing throughout the length of this study was the class-wide response-cost system which resulted in a loss of recess as a consequence of not completing all homework assigned. This procedure was class-wide, initiated by the lead classroom teacher on the first day of class, and continued throughout the remainder of the academic year.

\subsection{Dependent Measure and Data Collection}

The dependent measure was the percentage of homework tasks completed as assigned by the teacher. Homework tasks included both homework assignments and homework materials. Homework assignments were defined as the specific academic worksheets to be completed at home and turned into school the following morning. Homework materials included (a) textbook/reading book(s), (b) practice booklets, and/or (c) study guides for exams. Percentage of homework tasks completed was defined as the number of completed homework tasks (homework assignments and homework materials) divided by the number of homework tasks (homework 
assignment and homework materials) listed in a daily homework planner as written and directed by the classroom teacher, multiplied by 100. For example, if the daily homework planner listed one spelling worksheet, one science worksheet, and one language arts textbook for reading, and Mark brought home and completed only the spelling worksheet, the percentage of homework tasks completed was 33\% (1/3). The daily homework planner was always brought home by the student in his backpack so that an accurate percentage could be calculated.

Data were collected and recorded daily at home in the later afternoon by the first author who counted homework assignments and homework materials brought home, compared against expected homework assignments and homework materials as listed on the teacher's daily homework planner. The first author trained the classroom teacher on intervention implementation. The student's classroom teacher was the observer at the school, completing the daily homework planner to be sent home, collecting inter-observer agreement data, and during the intervention phase, monitoring/implementing intervention at the school. A third professional in the school collected procedural integrity data at both the school and home setting.

\subsection{Procedure}

\subsubsection{Baseline}

Baseline observation and data collection occurred in the home, after Mark arrived there from school. During the baseline phase, the student followed his typical school-day routine, and upon arrival at home dropped his backpack in the kitchen.

Each school day at 1:15 pm, the teacher reviewed for the whole class all homework assignments and materials for that night. All directions and reminders were orally delivered to the class as a whole, and the homework tasks were written on a homework board by the teacher. Information on the homework board mirrored the daily homework planner that each student had in front of them on their desks. At this time the teacher also checked each student's daily homework planner for $100 \%$ accuracy, ensuring the daily planner mirrored the homework board. It was the responsibility of the class to gather and take home all tasks and assignments listed on the daily homework planner. The last end-of-class bell sounded at 3:15 pm, with the school dismissal bell sounding at 3:20 pm.

At home, prior to homework time and without specific knowledge by the student, the first author collected baseline data by reviewing the teacher's daily homework planner, comparing that required number of homework tasks (assignments and materials) to actual homework tasks (assignments and materials) brought home that afternoon.

\subsubsection{Teacher and Student Training}

Following baseline, and prior to intervention the first author trained the classroom teacher on intervention implementation. Teacher training for intervention implementation involved the teacher (a) setting the wristwatch to alarm/vibrate mode, (b) verbally prompting the student to use the self-monitoring homework routine checklist (see Figure 1), and (c) monitoring Mark's preparation for departing school with the daily homework planner and homework tasks (materials and assignments) in his book bag. Once the teacher was trained to mastery on the intervention sequence, the teacher began instructing Mark how to (a) recognize the alarm as a prompt to begin the homework routine, (b) use of the self-monitoring homework routine checklist, and (c) pack his book bag with homework assignments and materials as he prepared for departing school.

For three consecutive days prior to the intervention phase, the teacher modeled for Mark how to use the self-monitoring homework routine checklist until the student displayed mastery. Day one the teacher verbally prompted each step of the intervention with the student, requiring the student to complete each step accurately. The teacher provided corrective feedback for any student errors. Days two and three, the teacher observed Mark as he independently completed each step of the intervention. After the third practice session, training ended and the intervention phase began.

\subsubsection{Intervention}

The intervention phase was implemented after the baseline phase and training period were completed. Identical to baseline, at 1:15 pm the teacher reviewed for the whole class all homework assignments and materials for that night. As in baseline, all directions and reminders were orally delivered to the class as a whole, and the homework tasks were written on a homework board. Information on the homework board mirrored the daily homework planners that each student has in front of them on their desks. The last end-of-class bell sounded at 3:15, with the school dismissal bell sounding at 3:20 pm.

The vibrating alarm wristwatch was designed to act as an antecedent prompt for Mark to get his homework 
binder with the attached self-monitoring routine checklist (see Figure 2). During intervention, the vibrating alarm wristwatch was set at home by Mark and the first author to coincide with the end-of-class bell, at 3:15 pm. Mark was in mathematics when his wristwatch prompted $(3: 15 \mathrm{pm})$ him to gather his homework materials and assignments to get ready to go home. The teacher monitored Mark during the 5-minutes (from 3:15 to 3:20 pm) to ensure the wristwatch alarm was accurately working and the student followed the self-monitoring routine procedure independently. The teacher provided no instruction during this time. No teacher prompting was ever required, and very little verbal praise was provided during this phase of the study.

The wristwatch included a button lock-out feature, so Mark could not accidently turn off or change the time. When the student arrived home, the first author reviewed with Mark the daily homework planner for the homework materials and assignments. Mark and the first author then checked the content of the book bag matching homework materials and assignments brought home compared against expected homework materials and assignments as listed on the teacher's daily homework planner. While at home, very little verbal praise was provided during this phase of the study.

\subsubsection{Continued Follow-Up}

When the intervention phase of the study ended, follow-up data continued to be collected and monitored once a week similar to the baseline procedures. Monthly follow-up checks were completed to monitor Mark's continued performance on homework completion. The first author conducted informal interviews with the teacher and Mark to document the potential benefits of the intervention, as well as meet with the teacher to record end of quarter grades.

\subsection{Experimental Design}

A single subject, within series ABAB was used for this study. After establishing an initial baseline of 14 sessions, absent of trend, a 3-day training period was completed. The 3-day training included the teacher, first author, and student. Following training, the intervention phase began. The first intervention phase was followed by a second baseline phase, a second intervention phase, and then a 5-month follow-up phase. A single subject ABAB research design allows for repeated, direct assessment within a single set of data across baseline and intervention phases. An ABAB single subject research design should (a) describe current behavior within a specific phase (baseline or intervention), (b) contrast current behavior within a specific phase to behavior from a previous phase (intervention to baseline or baseline to intervention), (c) predict, given the current behavior within a specific phase, future behavior within a specific phase (intervention phase to intervention phase or baseline phase to baseline phase), and (d) validate previous predictions (Kitchen \& Belfiore, 2013). The goal of single subject research is to establish experimental control (i.e., demonstrate through replication a functional/cause-effect relationship between the independent and dependent variables), while ruling out extraneous threats to validity by replication of baseline and intervention phases (Barlow, Nock, \& Hersen, 2009).

\subsection{Inter-Observer Agreement and Procedural Integrity}

Inter-observer agreement data were presented in terms of percentage agreement. Agreement data were collected by the teacher the following morning at school, in the same manner as was scored at home (e.g., count completed homework assignments and materials in backpack brought to school compared against expected homework assignments and materials as listed on the daily homework planner). A second independent researcher reviewed the first author's data collection sheet and compared it to the teacher's data sheet. Inter-observer agreement was calculated by the number of agreements divided by the number of disagreements plus number of agreements, and then multiplied by 100. Inter-observer agreement was 100\%, and agreement was collected during all baseline and intervention sessions.

For procedural integrity, a second independent researcher observed the first author (at home) and the classroom teacher (at school) across $80 \%$ of the intervention and maintenance sessions. Detailed procedures were required for the first author and teacher to follow during intervention phase to ensure accuracy at home and in school, and consistency across both settings. The procedural integrity routine includes the following steps; (a) at home in morning, first author and Mark set wristwatch alarm to vibrate at 3:15 pm, (b) at school, student initiates self-monitoring homework routine in response to watch alarm at 3:15, (c) at home in afternoon, first author and Mark checks daily homework planner and compare to materials brought home in backpack to homework planner. Agreement on the consistent implementation of the 3-step intervention procedures was $100 \%$

\section{Results}

\subsection{Homework Task Completion}

Figure 1 shows the results of intervention (vibrating wristwatch and self-monitoring homework routine checklist) 
on percentage homework task completion over a 7 -month period. The initial 14 -session baseline showed a mean percentage of homework task completion at $54.4 \%$, with wide variability, ranging between $0.0 \%-100 \%$ task completion. Although the range of baseline varied greatly session by session, baseline data did not trend upward or downward, ending with the last three baseline session at $50 \%, 67 \%$, and $50 \%$. Immediately following the 3 -day training, the mean percentage of homework completion increased to $100.0 \%$, with no variability across intervention sessions (i.e. all 6 intervention sessions remained at 100\%). A return to baseline resulted in both a reduction in the mean percentage of homework task completion to $71 \%$, and also a return to increased response variability, ranging between $28.6 \%-100 \%$. A return to intervention resulted in an immediate return and stabilization of results, with a mean percentage of homework completion at $100 \%$.

Follow-up checks at 1-month, 2-month, 3-month, 4-month, and 5-month showed a continued level of performance at $100 \%$ homework task completion, with one exception. During the follow-up phase, at the end of month-1, Mark was taken off his medication until the end of month-2. Off-medication data are represented by the three sessions during month- 2 of the follow-up phase, and showed a reduction in the percentage of homework completion to a mean of $75 \%$, but also a trending upward to $100 \%$ completion by the last session in month-2. New medication was introduced prior to data collection during month-3 of the follow-up phase.

As seen in Figure 1, breaks in sessions at end of baseline phase and before intervention phase began reflect 3 days of training prior to the intervention phase. Also seen in Figure 1, sessions 3, 7, 10, and 29 reflect no data collected because no homework assignments were given to the student on those days.

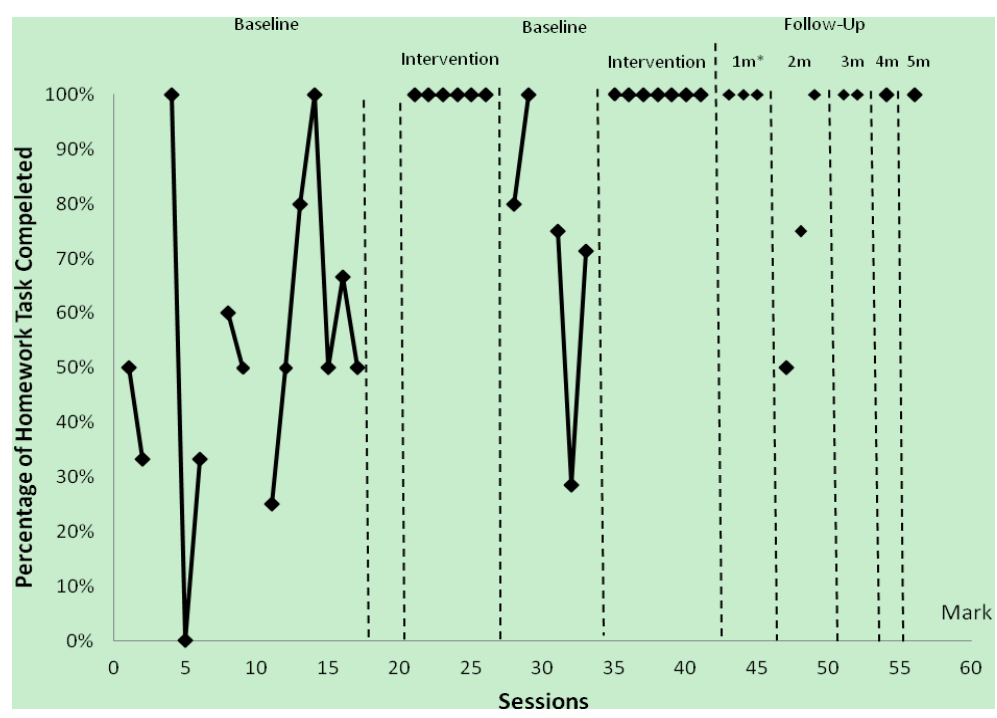

Figure 1. Percentage of homework tasks completed across baseline, intervention, and maintenance phases

Breaks in data set indicate days without homework being assigned. Maintenance was assessed at 1,2,3,4, and 5 month intervals. From the end of the month-1 through the end of month-2 the student was taken off ADHD medication $(*)$. New medication was prescribed, and began at the end of month-2.

\subsection{Social Validation}

At the end of the study, the teacher, parent, and Mark responded that the intervention was easy to implement and successful, resulting in more homework task completion. At the end of the study, Mark was asked a series of questions to gather information on social validity of the intervention (See Table 1). Mark responded that the watch looked cool and liked wearing it because no one knew the alarm was going off. Mark also noted a higher level of confidence in school preparedness, increased focus on the academic homework assignments, and more confidence in completing academic homework assignments independently. For example, there were occurrences throughout the study, as the teacher was talking/teaching/giving directions at 3:15, Mark would point to his watch to prompt the teacher that it was time to get ready. This communication was completely initiated by the student, occurring once every two or three weeks. Additionally, when speaking to the teacher at the end of the study, the teacher indicated one positive aspect of the intervention was that the watch and SM routine did not distract or 
disturb the general classroom operations. Currently, Mark continues to wear the vibrating alarm watch daily, while choosing not to use the homework routine checklist.

Table 1. End-of-study student social validity survey (student response in parentheses)

\begin{tabular}{l}
\hline (Answer YES or NO) \\
\hline 1. By using the vibrating alarm watch, I was able to focus on getting my homework materials (YES) \\
2. I feel the watch is cool to wear (YES) \\
3. I feel others noticed my watch and I was embarrassed by it (NO) \\
4. I feel more confident that I can be prepared for school (YES) \\
5. I feel more confident I can learn to do things independently (YES) \\
6. I will continue to wear my watch (YES)
\end{tabular}

\subsection{Academic Grades}

In addition to the success Mark showed in increasing homework task completion, he also improved academically. Based on school quarter grades, Mark improved in two subjects, (a) mathematics in quarter one Mark had a grade of $\mathrm{C}$, while mathematics in quarter three he earned a grade of $\mathrm{B}$, and (b) science in quarter one Mark had a grade of $\mathrm{C}$, while science in quarter three he earned a grade of $\mathrm{A}$. All other academic grades remained the same across the three quarters, (a) language arts remained at the grade B level, and (b) social studies remained at the grade A level.

\section{Discussion}

Prior to this intervention, Mark often forgot to place all homework tasks in his book bag, resulting in a loss of free time, recess, and homework points. Results of this study showed that a simple antecedent prompt paired with a self-monitoring homework routine resulted in an increase in homework task completion. The non-obtrusive, automated vibrating wristwatch may have served as a discriminative stimulus $\left(\mathrm{S}^{\mathrm{D}}\right)$ occasioning Mark's behavior to get his homework binder and SM homework routine checklist (Figure 2). In turn, the SM homework routine checklist may have served as an $\mathrm{S}^{\mathrm{D}}$, occasioning Mark's behavior to place all homework tasks and assignments in his book bag before leaving school. Both responses, (a) getting the binder/SM checklist and (b) placing materials in book bag were differentially reinforced by access to free time/recess and homework points as a result of increased homework completion, which in turn may have had a positive impact on academic grades.

The intervention here was the result of a collaborative exchange between home, teacher, and caregiver. This approach aligns with Masten and Coatsworth (1998) suggestion to target primary caregiver involvement as a key to improving academic success in children. In the role of primary caregiver, the first author (a) accurately monitored the target behavior and implemented intervention steps, which extended over a period of seven months (i.e., three academic school quarters), (b) ensured the proper administration of, and change in, medication, and (c) maintained a professional relationship with the classroom teacher, ensuring consistency of intervention across both school and home settings. For example, when Mark discontinued his medication (Concerta), due to lack of weight gain at month-2 of the maintenance phase, and when he started his new medication (Focalin XR), he continued to follow the correct homework intervention procedure, maintaining $100 \%$ homework task completion at month-3,-month-4, and month-5. Given the unique home-school relationship necessary for an effective homework program, the current study could not have been completed without the role the mother provided. Sheridan (2009) stressed that the ability of care givers to control environments over time, and to be a consistent influence and part of the contextual intervention, is essential for the fidelity and contiguity of academic skills. In this study, the parent, acting as a problem-solver and an equal partner in the school-home intervention implementation process further enhanced both the procedural accountability (i.e., "Was the intervention effective, efficient, and socially valid?"), and the procedural fidelity (i.e., "Were the evidence-based practices delivered in a consistent manner, as prescribed?") (Belfiore, Fritts, \& Herman, 2008).

This study represents what Belfiore and colleagues $(2002 ; 2008 ; 2013)$ described as behavioral analytic action research, a research methodology that links applied behavioral research with evidenced-based practices. Behavioral analytic action research moves beyond what has typically been described as action research (e.g., 
Hendricks, 2009; Johnson, 2002; Sardo-Brown, Welsch, \& Bolton, 1995) or teacher action research (Pine, 2009). From a behavioral analytic position, two key variables are missing from the action research literature. First, action research/teacher action research makes no mention of the need for experimental control (Belfiore, Lee, Scheeler, \& Klein, 2002). With the omission of experimental control within an action research framework it becomes virtually impossible to (a) determine with any certainty the relationship between intervention and student performance, which in turn minimizes (b) outcome dissemination of results to an external audience. Second, action research makes no attempt to link classroom interventions or teaching strategies to a basic-conceptual foundation (Belfiore, et al., 2002). Yes, teacher-identified concerns prompt teacher-gathered data (Calhoun, 1993), but the connection of practice to basic research or theory does not occur. The omission of experimental control and a conceptual link promotes a random-like approach to intervention strategies, increasing the likelihood of intervention ineffectiveness and time mismanagement. Behavioral analytic action research incorporates those variables of action research not consistently found in applied behavioral research (e.g., intervention carried out by the classroom teacher/practitioner in the context of the natural setting), and those variables of applied behavior analysis not consistently found in action research (e.g., establishing experimental control, and an overt link to the conceptual base).

Belfiore et al., (2002) suggested behavioral analytic action research provides the external validity necessary to extend the basic-applied research continuum into more naturalistic settings, while maintaining the control necessary for behavior analysis and external dissemination of results. Belfiore, Pulley-Basile, \& Lee, (2008) described behavioral analytic action research as (a) predicated on a real world problem, (b) conceptually linked to behavioral theory and applied research, (c) carried out exclusively by classroom staff within the context of the general classroom environment, (d) utilizing direct methods of data collection gathered within the typical classroom structure, (e) implemented usually within a single subject methodology, and (f) establishing experimental control via demonstrating a functional relationship. The current study expands the role of direct care classroom staff to include parents/caregivers, and also expands the general classroom setting to include the home. The additional inclusion of the parents input, and the home as a research setting adds to the richness of what real, day-to-day problems encompass. Additionally, practitioners and caregivers working in the context of behavioral analytic action research can extend the external validity of applied behavioral research, allowing for expanded dissemination of results beyond the local audience (Kitchen \& Belfiore, 2013).

Although successful, the outcome of this study represented a single case, examining the effects of intervention with one elementary-level student with ADHD. Future research should assess a larger selection of care-givers, as well as participants across different grade-levels and without ADHD. Additionally, future research should also evaluate the impact of the current intervention as a class-wide strategy. Lastly, if the current study showed the effectiveness of a non-intrusive antecedent and self-monitoring chart on a homework completion, other related routines, both academic (e.g., homework, study skills, test preparation), and non-academic (e.g., playground participation, evening bedtime preparation) may benefit from such an intervention, and should be evaluated.

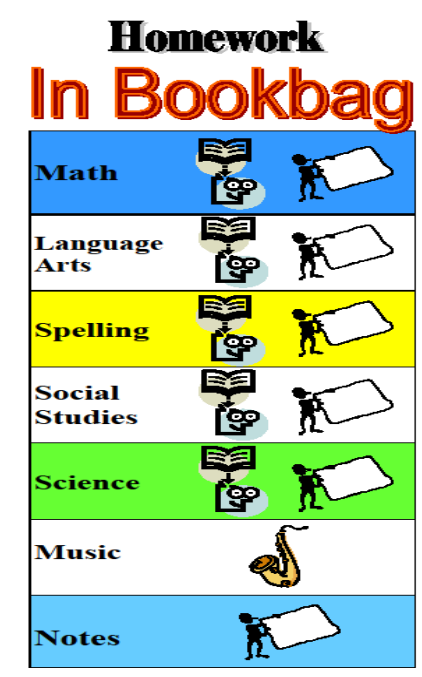

Figure 2. Self-monitoring homework routine checklist used by mark during intervention and maintenance phases of the study 


\section{References}

Amato-Zech, N. A., Hoff, K. E., \& Doepke, K. J. (2006). Increasing on-task behavior in the classroom: Extension of self-monitoring strategies. Psychology in the Schools, 43(2), 211-221. http://dx.doi.org/10.1002/pits.20137

Axelrod, M. I., Zhe, E. J., Haugen, K. A., \& Klein, J. A. (2009). Self-management of on-task homework behavior: A promising strategy for adolescents with attention and behavior problems. School Psychology Review, 38, 325-333.

Barlow, D. H., Nock, M. K., \& Hersen, M. (2009). Single case experimental designs: Strategies for studying behavior change. NY: Pearson.

Belfiore, P. J., Fritts, K. M., \& Herman, B. C. (2008). The role of procedural integrity: Using self-monitoring to enhance discrete trial instruction (DTI). Focus on Autism and Other Developmental Disabilities, 23(2), 95-102. http://dx.doi.org/10.1177/1088357607311445

Belfiore, P. J., \& Hutchinson, J. M. (1998). Enhancing academic achievement through related routines: A functional approach. New York, NY US: Plenum Press.

Belfiore, P. J., Lee, D. L., Scheeler, M. C., \& Klein, D. (2002). Implications of behavioral momentum and academic achievement for students with behavioral disorders: Theory, application, and practice. Psychology in the Schools, 39, 171-179. http://dx.doi.org/10.1002/pits.10028

Belfiore, P. J., Pulley-Basile, S. P., \& Lee, D. L. (2008). Using a high probability command sequence to increase classroom compliance: The role of behavioral momentum. Journal of Behavioral Education, 17(2), 160-171. http://dx.doi.org/10.1007/s10864-007-9054-x

Bryan, T., \& Burstein, K. (2004). Improving homework completion and academic performance: Lessons from special education. Theory into Practice, 43, 213-219. http://dx.doi.org/10.1207/s15430421tip4303 7

Calhoun, E. F. (1993). Action research: Three approaches. Educational Leadership, 50, 62-65.

Cancio, E. J., West, R. P., \& Young, K. R. (2004). Improving mathematics homework completion and accuracy of students with EBD through self-management and parent participation. Journal of Emotional and Behavioral Disorders, 12, 9-22. http://dx.doi.org/10.1177/10634266040120010201

Currie, D., Lee, D. L., \& Scheeler, M. C. (2005). Using PDAs to increase the homework completion of students with ADHD. Journal of Evidenced-Based Practices for Schools, 6, 151-162.

Hendricks, C. (2009). Improving schools through action research: A comprehensive guide for educators. Columbus, OH: Pearson.

Hooper-Dempsey, K. V., Bassler, O. C., \& Burow, W. (1995). Parents' reported involvement in student's homework: Strategies and practices. The Elementary School Journal, 95, 35-450.

Johnson, A. P. (2002). A short guide to action research. Boston: Allyn and Bacon.

Kim, E. M., Sheridan, S. M., Kwon, K., \& Koziol, N. (2013). Parent beliefs and children's social-behavioral functioning: The mediating role of parent-teacher relationships. Journal of School Psychology, 51(2), 175-185. http://dx.doi.org/10.1016/j.jsp.2013.01.003

Kitchen, T., \& Belfiore, P. J. (2013). Increasing outcomes for individuals with intellectual and developmental disabilities through data-based mechanisms for staff training and performance feedback. In D. F. Mancini, \& C. M. Greco (Eds.), Intellectual Disability: Management, Causes, and Social Perceptions. Hauppauge, NY: Nova Science Publishers.

Legge, D. B., DeBar, R. M., \& Alber-Morgan, S. R. (2010). The effects of self-monitoring with a MotivAider ${ }^{\circledR}$ on the on-task behavior of children with autism and other disabilities. Journal of Behavior Assessment and Intervention Children, 1, 43-52.

Masten, A. S., \& Coatsworth, J. D. (1998). The development of competence in favorable and unfavorable environments: Lessons from research on successful children. American Psychologist, 53(2), 205-220. http://dx.doi.org/10.1037/0003-066X.53.2.205

Mathes, M., \& Bender, W. (1997). The effects of self-monitoring on children with Attention-Deficit /Hyperactivity Disorder who are receiving pharmacological interventions. Remedial and Special Education, 18, 121-134. http://dx.doi.org/10.1177/074193259701800206 
Merriman, D., \& Codding, R. (2008). The effects of coaching on mathematics homework completion and accuracy of high school students with attention-Deficit/Hyperactivity disorder. Journal of Behavioral Education, 17(4), 339-355. http://dx.doi.org/10.1007/s10864-008-9072-3

National Institute of Mental Health. (2008). Attention Deficit Hyperactivity Disorder (ADHD.) Retrieved May 3, 2013 from http://www.nimh.nih.gov/health/publications/attention-deficit-hyperactivity-disorder/what-is-attention-defic it-hyperactivity-disorder.shtml

Olympia, D. E., Sheridan, S. M., Jenson, W. R., \& Andrews, D. (1994). Using student-managed interventions to increase homework completion and accuracy. Journal of Applied Behavior Analysis, 27, 85-99. http://dx.doi.org/10.1901/jaba.1994.27-85

Ortho-McNeil-Janssen Pharmaceutical, Inc. (2009). Concerta. Retrieved Oct. 20, 2010, from http://www.concerta.net/children/adhd-treatment-concerta-basics.html

Patall, E. A., Cooper, H., \& Robinson, J. C. (2008). Parent involvement in homework: A research synthesis. Review of Educational Research, 78(4), 1039-1101. http://dx.doi.org/10.3102/0034654308325185

Pine, G. J. (2009). Teacher action research: Building knowledge democracies. Thousand Oaks, CA: Sage.

Power, T. J., Werba, B. E., Watkins, M. W., Angelucci, J. G., \& Eiraldi, R. B. (2006). Patterns of parent-reported homework problems among ADHD-referred and non-referred children. School Psychology Quarterly, 21(1), 13-33. http://dx.doi.org/10.1521/scpq.2006.21.1.13

Ramdass, D., \& Zimmerman, B. J. (2011). Developing self-regulation skills: The important role of homework. Journal of Advanced Academics, 22, 194-218. http://dx.doi.org/10.1177/1932202X1102200202

Sardo-Brown, D.,Welsch, L., \& Bolton, D. L. (1995). Practical strategies for facilitating classroom teachers' involvement in action research. Education, 115, 553-559.

Sheridan, S. M. (2009). Homework intervention for children with attention and learning problems: Where is the "home" in "homework?" Psychology Review, 38, 334-337.

\section{Copyrights}

Copyright for this article is retained by the author(s), with first publication rights granted to the journal.

This is an open-access article distributed under the terms and conditions of the Creative Commons Attribution license (http://creativecommons.org/licenses/by/3.0/). 